Review Article

\title{
Rehabilitation Treatment and Progress of Traumatic Brain Injury Dysfunction
}

\author{
Baoqi Dang, ${ }^{1,2}$ Wenli Chen, ${ }^{2}$ Weichun He, ${ }^{2}$ and Gang Chen ${ }^{1}$ \\ ${ }^{1}$ Department of Neurosurgery \& Brain and Nerve Research Laboratory, The First Affiliated Hospital of Soochow University, \\ 188 Shizi Street, Suzhou 215006, China \\ ${ }^{2}$ Department of Rehabilitation Medicine, Zhangjiagang Hospital of Traditional Chinese Medicine, Suzhou 215600, China
}

Correspondence should be addressed to Gang Chen; nju_neurosurgery@163.com

Received 29 November 2016; Revised 28 February 2017; Accepted 7 March 2017; Published 11 April 2017

Academic Editor: Aaron S. Dumont

Copyright (c) 2017 Baoqi Dang et al. This is an open access article distributed under the Creative Commons Attribution License, which permits unrestricted use, distribution, and reproduction in any medium, provided the original work is properly cited.

Traumatic brain injury (TBI) is a major cause of chronic disability. Worldwide, it is the leading cause of disability in the under 40 s. Behavioral problems, mood, cognition, particularly memory, attention, and executive function are commonly impaired by TBI. Spending to assist, TBI survivors with disabilities are estimated to be costly per year. Such impaired functional outcomes following TBI can be improved via various rehabilitative approaches. The objective of the present paper is to review the current rehabilitation treatment of traumatic brain injury in adults.

\section{Introduction}

Traumatic brain injury (TBI) refers to blunt, penetrating, or acceleration/deceleration force-derived craniocerebral injury, which causes symptoms such as decline in level of awareness or consciousness, memory loss or forgetfulness, other neurological or neuropsychological abnormalities, and even death. TBI is a critical public health and socioeconomic problem throughout the world. The incidence of TBI has been increasing annually. According to the World Health Organization, TBI will be a major health problem and the main reason for disability in 2020 [1]. Primary and secondary TBIs cause temporary and/or permanent dysfunction in the brain, which limits a patient's activities, affects participation in society, and lowers quality of life. This can lead to depression and other chronic diseases in TBI patients $[2,3]$. This article reviews current rehabilitation treatment for TBI.

\section{Hyperbaric Oxygen Therapy (HBOT) Relieves TBI}

Hyperbaric oxygen therapy (HBOT) is defined as the inhalation of $100 \%$ oxygen under the pressure greater than 1 atmosphere absolute (ATA) $(1 \mathrm{ATA}=101.3 \mathrm{kPa}) . \mathrm{HBOT}$ is a current interest in the field of neurological diseases and has been proved to inhibit apoptosis, suppress inflammation, protect the integrity of blood-brain barrier, and promote angiogenesis and neurogenesis $[4,5]$.

The major pathogenic mechanisms of TBI include ischemia and hypoxia in brain tissues, resulting in parenchymal softening with necrosis. To date, HBOT is one of the most important clinical therapies for TBI. A study by Lin et al. [6] showed that 2.0 atmospheres absolute (ATA) oxygen in HBOT for 5 consecutive days (once per day, 1 hour per session) resulted in overexpression of the $70 \mathrm{kDa}$ heat shock protein (HSP-70) and attenuated cerebral edema, oxidative damage in the hippocampus, and cognitive impairment in a rat model in a simulated high-altitude environment $(9.7 \%$ oxygen concentration, 6000 meter altitude, and 0.47 ATA) for 3 consecutive days. Harch et al. [7] treated 16 TBI, post-TBI syndrome, and posttraumatic stress disorder (PTSD) patients with 40 sessions of $1.5 \mathrm{ATA} / 60$ minutes of HBOT for 30 days, which greatly improved symptoms, results of neurological examinations, comprehensive IQ tests, and cognition functions. A study by Geng et al. [8] showed that HBOT may 
suppress activation of inflammasome signals, thereby alleviating TBI.

In chronic brain injury, HBOT improved cerebral blood flow $(\mathrm{CBF})$ and ameliorated the neuropsychological disorders $[9,10]$. HBOT has also been reported to show positive effects by improving the quality of life in patients with postconcussion syndrome or mild TBI at late chronic stage $[7,11,12]$. In severe TBI, HBOT has reduced mortality and enhanced functional outcome [13-15]. These researches suggested the successful use of intensive $\mathrm{HBO}$ as a treatment in TBI patients.

\section{Noninvasive Brain Stimulation Benefits the Treatment of TBI}

To date, several technologies have been developed. The most common technologies are transcranial magnetic stimulation (TMS) and transcranial direct current stimulation (tDCS). Repetitive transcranial magnetic stimulation (rTMS) is a painless, noninvasive, easily operated treatment with few adverse reactions. It has specific effects in rehabilitation of TBI patients [16]. Depending on the frequency used, rTMS alters neuronal excitability by generating excitatory $(>5 \mathrm{~Hz})$ or inhibitory $(1 \mathrm{~Hz})$ activity, which can last for several hours $[17,18]$. As a noninvasive brain stimulation technique, rTMS has successfully treated schizophrenia, depression, Parkinson's disease, aphasia, unilateral neglect, and cognitive impairment [19-24]. Neville et al. [25] conducted a doubleblind randomized controlled trial with 36 TBI patients who were randomly and equally divided into 2 groups. TBI patients in the treatment group received 10 sessions of high-frequency rTMS $(10 \mathrm{~Hz})$ over the left dorsolateral prefrontal cortex (DLPFC), and TBI patients in the sham group received pseudostimulation. The patients underwent neuropsychological assessment 1 week before and then 1 week and 3 months after rTMS to evaluate direct and delayed effects. The results showed that rTMS could improve depression and cognitive function after TBI.

Dhaliwal et al. [26] and Li et al. [27] recently reported that cerebral stimulation had potential effects on TBI treatment. Although these 2 groups studied non-athletic-related injuries, they indicated the safety and potential benefits of cerebral stimulation for TBI patients. Several studies have shown that rTMS and tDCS reduce TBI-associated depression, tinnitus, neglect, memory deficits, and attention disorders [26, 27]. Middleton et al. [28] also reported that 2 TBI patients who received dual-hemisphere tDCS ( 1 patient had stroke and TBI) for 6 months showed significant improvement based on the upper extremity Fugl-Meyer scale. These studies demonstrate that post-TBI cerebral stimulation is safe and has potential benefits.

\section{Virtual Reality Evaluates the Function and Improves the Prognosis of TBI}

Computer-aided training combined with audial and visual stimulations to simulate audial, visual, and gameassociated intuitive trainings that engage different components of impairment, such as memory, attention, and visual perception, greatly improves patient interest and enthusiasm in participation. Development of a computer-aided training system, especially virtual reality (VR) technology, promotes integration between computer technology and cognitive science that has incomparable advantages for assessment and training of cognitive impairment compared with cognitive training by rehabilitation therapists [29-31]. During the training process, personal, customized procedures are used to reduce the duration of the direct contact between the therapist and the patient. Studies have shown that computer-aided strategies improve patient attention, memory, and execution capabilities [32, 33]. VR training also improves patient mood through audial and visual feedback that lets patients experience emotional success and minimizes patient anxiety during treatment [34]. It also promotes persistence since patients practice until they succeed. In addition, a VR training system provides a comprehensive evaluation of patient motor function, cognitive function, daily life skills, and social skills. It directly analyzes the data and presents a written report for comparison of pre- and posttreatment conditions, which help in determining treatment goals, selecting treatment options, and evaluating training effects to achieve a perfect combination of interactive training and exercise, cognitive training, and rehabilitation assessment [35].

\section{Limb or Organ Function Reconstruction following TBI}

Functional electrical stimulation (FES) is a low-frequency pulse current that is used to stimulate limb or organ dysfunction. Its effects replace or correct lost function in limbs and organs. By adjusting the advanced nerve center, FES promotes functional reconstruction in patients [36]. Task-oriented functional electrical stimulation (TFES) is a combination of bilateral exercise, repetitive training, task-oriented therapy, and FES, and preliminary results have indicated positive outcomes [37-40].

Treatment outcomes of TFES are better than those of FES and conventional therapy. A possible explanation may combine the effects of FES and task-oriented therapies as well as the synergistic effect of this combination therapy. IftimeNielsen et al. [41] confirmed a synergistic effect between proactive attitude of patients and FES therapy. Makowski et al. [42] showed that a combination of FES therapy and conscious activity affected action stimulated by FES. Under the effect of FES, a weak and voluntary effort can produce greater reach and movement.

Calabrò et al. [43] conducted 2 different types of intensive rehabilitation training for a 34-year-old male with dysphagia after TBI, which included conventional rehabilitation training and a combination of conventional rehabilitation training and VitalStim electrical stimulation therapy for 6 weeks to access his specific swallowing function and electrophysiological parameters before and after treatment. The results showed that only VitalStim point simulation significantly improved the swallowing function of the patient. This patient could eventually and safely eat solid food after the treatment. 


\section{TBI Benefits from Behavioral, Emotional, and Family Therapies}

TBI affects a patient's emotions, behavioral stability, and selfconfidence. Primary caregivers of TBI patients experience considerable emotional stress and sense of burden. Albert et al. [44] showed that low-cost interventions relieve the burden of caregivers and improve their satisfaction. A study by Sinnakaruppan et al. [45] showed that family education programs for caregivers and TBI family members help relieve stress and strengthen coping abilities.

Common behavioral changes after TBI often include anger, depression, anxiety, and verbal or physical aggression. Emotional stability of TBI patients is necessary; otherwise, these patients cannot participate in and benefit from the rehabilitation processes. Psychotherapy (individual and group) emphasizes emotional and behavioral therapies. Studies show that training in good coping skills and anger management can reduce patient aggression. In addition, Baker et al. [46] showed that music therapy demonstrated an improvement in patient emotion and anger problems.

\section{Basic Research on TBI Rehabilitation in Recent Years}

In recent years, the basic research on traumatic brain injury rehabilitation increase gradually [47-51]. A recent review suggests that rat models and closed head impacts have dominated the field of behavioral testing in animal models of juvenile TBI. Both motor and cognitive functions seem to be affected [47]. A latest study revealed that long-term spatial learning-memory deficits are dependent on the severity of destruction in the white matter and hippocampus. Therapeutic strategies targeting both the white matter and hippocampus may be needed to improve the neurological functions in TBI victims [50].

Studies have shown that the major cause of death after TBI is neuronal death and rupture of blood vessels. Nerve regeneration and angiogenesis play key roles in functional recovery [52-54]. Circulating endothelial progenitor cells (EPCs) are involved in angiogenesis $[55,56]$ and have been confirmed to reduce infarct volume, increase capillary density, and improve myocardial blood perfusion and limb ischemia in animal models $[57,58]$. Erythropoietin (EPO) promotes proliferation and differentiation of red blood cells and has been used in clinical treatment of anemia, prevention of spinal cord injury [59], retinal ischemia [60],skeletal muscle ischemia [58],pulmonary hypertension [61], and myocardial ischemia-reperfusion injury $[62,63]$. It is also used for prevention of TBI by enhancing antiapoptotic [59, 64], anti-inflammatory [60], and neuroprotective effects [65, 66]. Through mobilization of endothelial progenitor cells, EPO promotes angiogenesis and reduces nerve cell death, which improves functional outcomes after stroke [67-69]. Data of Wang et al. [49] showed that recombinant human EPO mobilized endothelial progenitor cells and angiogenesis to improve the functional prognosis of TBI in rats.

In summary, rehabilitation is essential after TBI treatment. Studies on the timing of corresponding rehabilitation in stroke research are common. However, the optimal window for TBI rehabilitation is rarely reported. Andelic et al. [70] divided 61 patients with severe TBI into 2 groups: the experimental group with early intervention of rehabilitation training and the control group with delayed rehabilitation training. The Glasgow Outcome Scale Extended (GOSE) and the Disability Rating Scale (DRS) were used to rate the 2 groups 12 months after training. The results demonstrated that the experimental group had significantly higher GOSE and DRS scores compared with the control group, which indicated that early intervention of rehabilitation training achieved better treatment outcomes. However, due to the complexity of TBI, an inadequate sample size, and lack of an appropriate control group, clinical rehabilitation studies have encountered significant challenges. For noninvasive brain stimulation, stimulation frequency, precise positioning, and course of treatment are closely associated with treatment efficacy. A large-scale randomized controlled trial is necessary in further studies, and additional research in this direction will extend the rehabilitation prospects of TBI.

\section{Conflicts of Interest}

The authors declare that there is no conflict of interest regarding the publication of this paper.

\section{Authors' Contributions}

Baoqi Dang and Wenli Chen contributed equally to this work.

\section{Acknowledgments}

This work was supported by the Suzhou Key Medical Center (Szzx201501)-grants from the National Natural Science Foundation of China (nos. 81571115, 81422013, and 81471196), Scientific Department of Jiangsu Province (no. BL2014045), Suzhou Government (nos. SZS201413, SYS201608, and LCZX201601), Jiangsu Province (no. 16KJB320008).

\section{References}

[1] A. A. Hyder, C. A. Wunderlich, P. Puvanachandra, G. Gururaj, and O. C. Kobusingye, "The impact of traumatic brain injuries: a global perspective," NeuroRehabilitation, vol. 22, no. 5, pp. 341-353, 2007.

[2] B. T. Mausbach, E. A. Chattillion, R. C. Moore, S. K. Roepke, C. A. Depp, and S. Roesch, "Activity restriction and depression in medical patients and their caregivers: a meta-analysis," Clinical Psychology Review, vol. 31, no. 6, pp. 900-908, 2011.

[3] K. A. Cappa, J. C. Conger, and A. J. Conger, "Injury severity and outcome: a meta-analysis of prospective studies on TBI outcome," Health Psychology, vol. 30, no. 5, pp. 542-560, 2011.

[4] C. Braswell and D. T. Crowe, "Hyperbaric oxygen therapy," Compendium on Continuing Education for the Practising Veterinarian, vol. 34, no. 3, pp. E1-E5, E6, 2012.

[5] E. C. Sanchez, "Mechanisms of action of hyperbaric oxygenation in stroke: a review," Critical Care Nursing Quarterly, vol. 36, no. 3, pp. 290-298, 2013. 
[6] H. Lin, C. P. Chang, H. J. Lin, M. T. Lin, and C. C. Tsai, "Attenuating brain edema, hippocampal oxidative stress, and cognitive dysfunction in rats using hyperbaric oxygen preconditioning during simulated high-altitude exposure," Journal of Trauma and Acute Care Surgery, vol. 72, no. 5, pp. 1220-1227, 2012.

[7] P. G. Harch, S. R. Andrews, E. F. Fogarty et al., “A phase I study of low-pressure hyperbaric oxygen therapy for blastinduced post-concussion syndrome and post-traumatic stress disorder," Journal of Neurotrauma, vol. 29, no. 1, pp. 168$185,2012$.

[8] F. Geng, Y. Ma, T. Xing, X. Zhuang, J. Zhu, and L. Yao, "Effects of hyperbaric oxygen therapy on Inflammasome signaling after traumatic brain injury," Neuroimmunomodulation, vol. 23, no. 2, pp. 122-129, 2016.

[9] Z. L. Golden, R. Neubauer, C. J. Golden, L. Greene, J. Marsh, and A. Mleko, "Improvement in cerebral metabolism in chronic brain injury after hyperbaric oxygen therapy," International Journal of Neuroscience, vol. 112, no. 2, pp. 119-131, 2002.

[10] Z. Golden, C. J. Golden, and R. A. Neubauer, "Improving neuropsychological function after chronic brain injury with hyperbaric oxygen," Disability and Rehabilitation, vol. 28, no. 22, pp. 1379-1386, 2006.

[11] R. Boussi-Gross, H. Golan, G. Fishlev et al., "Hyperbaric oxygen therapy can improve post concussion syndrome years after mild traumatic brain injury - randomized prospective trial," PloS One, vol. 8, no. 11, article e79995, 2013.

[12] P. G. Harch, E. F. Fogarty, P. K. Staab, and K. Van Meter, "Low pressure hyperbaric oxygen therapy and SPECT brain imaging in the treatment of blast-induced chronic traumatic brain injury (post-concussion syndrome) and post traumatic stress disorder: a case report," Cases Journal, vol. 2, p. 6538, 2009.

[13] L. Q. Lv, L. J. Hou, M. K. Yu, X. H. Ding, X. Q. Qi, and Y. C. Lu, "Hyperbaric oxygen therapy in the management of paroxysmal sympathetic hyperactivity after severe traumatic brain injury: a report of 6 cases," Archives of Physical Medicine and Rehabilitation, vol. 92, no. 9, pp. 1515-1518, 2011.

[14] G. L. Rockswold, S. E. Ford, D. C. Anderson, T. A. Bergman, and R. E. Sherman, "Results of a prospective randomized trial for treatment of severely brain-injured patients with hyperbaric oxygen," Journal of Neurosurgery, vol. 76, no. 6, pp. 929-934, 1992.

[15] A. Prakash, S. V. Parelkar, S. N. Oak et al., "Role of hyperbaric oxygen therapy in severe head injury in children," Journal of Pediatric Neurosciences, vol. 7, no. 1, pp. 4-8, 2012.

[16] P. M. Kreuzer, M. Landgrebe, E. Frank, and B. Langguth, "Repetitive transcranial magnetic stimulation for the treatment of chronic tinnitus after traumatic brain injury: a case study," The Journal of Head Trauma Rehabilitation, vol. 28, no. 5, pp. 386-389, 2013.

[17] E. M. Wassermann, A. Samii, B. Mercuri et al., "Responses to paired transcranial magnetic stimuli in resting, active, and recently activated muscles," Experimental Brain Research, vol. 109, no. 1, pp. 158-163, 1996.

[18] S. Rossi, M. Hallett, P. M. Rossini, A. Pascual-Leone, and Safety of TMS Consensus Group, "Safety, ethical considerations, and application guidelines for the use of transcranial magnetic stimulation in clinical practice and research," Clinical Neurophysiology, vol. 120, no. 12, pp. 2008-2039, 2009.

[19] W. Yang, T. T. Liu, X. B. Song et al., "Comparison of different stimulation parameters of repetitive transcranial magnetic stimulation for unilateral spatial neglect in stroke patients,"
Journal of the Neurological Sciences, vol. 359, no. 1-2, pp. 219-225, 2015.

[20] C. Miniussi, S. F. Cappa, L. G. Cohen et al., "Efficacy of repetitive transcranial magnetic stimulation/transcranial direct current stimulation in cognitive neurorehabilitation," Brain Stimulation, vol. 1, no. 4, pp. 326-336, 2008.

[21] T. Wobrock, B. Guse, J. Cordes et al., "Left prefrontal highfrequency repetitive transcranial magnetic stimulation for the treatment of schizophrenia with predominant negative symptoms: a sham-controlled, randomized multicenter trial," Biological Psychiatry, vol. 77, no. 11, pp. 979-988, 2015.

[22] Y. Li, Y. Qu, M. Yuan, and T. Du, "Low-frequency repetitive transcranial magnetic stimulation for patients with aphasia after stoke: a meta-analysis," Journal of Rehabilitation Medicine, vol. 47, no. 8, pp. 675-681, 2015.

[23] S. Pallanti, A. Di Rollo, S. Antonini, G. Cauli, E. Hollander, and L. Quercioli, "Low-frequency rTMS over right dorsolateral prefrontal cortex in the treatment of resistant depression: cognitive improvement is independent from clinical response, resting motor threshold is related to clinical response," Neuropsychobiology, vol. 65, no. 4, pp. 227-235, 2012.

[24] M. Vonloh, R. Chen, and B. Kluger, "Safety of transcranial magnetic stimulation in Parkinson's disease: a review of the literature," Parkinsonism \& Related Disorders, vol. 19, no. 6, pp. 573-585, 2013.

[25] I. S. Neville, C. Y. Hayashi, H. S. El et al., "Repetitive transcranial magnetic stimulation (rTMS) for the cognitive rehabilitation of traumatic brain injury (TBI) victims: study protocol for a randomized controlled trial," Trials, vol. 16, p. 440, 2015.

[26] S. K. Dhaliwal, B. P. Meek, and M. M. Modirrousta, "Noninvasive brain stimulation for the treatment of symptoms following traumatic brain injury," Frontiers in Psychiatry, vol. 6, p. 119, 2015.

[27] S. Li, A. L. Zaninotto, I. S. Neville, W. S. Paiva, D. Nunn, and F. Fregni, "Clinical utility of brain stimulation modalities following traumatic brain injury: current evidence," Neuropsychiatric Disease and Treatment, vol. 11, pp. 1573-1586, 2015.

[28] A. Middleton, S. L. Fritz, D. M. Liuzzo, R. Newman-Norlund, and T. M. Herter, "Using clinical and robotic assessment tools to examine the feasibility of pairing tDCS with upper extremity physical therapy in patients with stroke and TBI: a consideration-of-concept pilot study," NeuroRehabilitation, vol. 35, no. 4, pp. 741-754, 2014.

[29] G. Riva, F. Mantovani, and A. Gaggioli, "Presence and rehabilitation: toward second-generation virtual reality applications in neuropsychology," Journal of Neuroengineering and Rehabilitation, vol. 1, no. 1, p. 9, 2004.

[30] F. D. Rose, B. M. Brooks, and A. A. Rizzo, "Virtual reality in brain damage rehabilitation: review," Cyberpsychology \& Behavior, vol. 8, no. 3, pp. 241-262, 2005, 263-271.

[31] P. J. Standen and D. J. Brown, "Virtual reality in the rehabilitation of people with intellectual disabilities: review," Cyberpsychology \& Behavior, vol. 8, no. 3, pp. 272-282, 2005, 283-288.

[32] S. F. Tam and W. K. Man, "Evaluating computer-assisted memory retraining programmes for people with post-head injury amnesia," Brain Injury, vol. 18, no. 5, pp. 461-470, 2004.

[33] T. Bergquist, C. Gehl, J. Mandrekar et al., "The effect of internet-based cognitive rehabilitation in persons with memory impairments after severe traumatic brain injury," Brain Injury, vol. 23, no. 10, pp. 790-799, 2009. 
[34] K. Verhoeven, G. Crombez, C. Eccleston, D. M. Van Ryckeghem, S. Morley, and S. Van Damme, "The role of motivation in distracting attention away from pain: an experimental study," Pain, vol. 149, no. 2, pp. 229-234, 2010.

[35] G. Burdea, V. Popescu, V. Hentz, and K. Colbert, "Virtual reality-based orthopedic telerehabilitation," IEEE Transactions on Rehabilitation Engineering, vol. 8, no. 3, pp. 430-432, 2000.

[36] T. Hamada, T. Hayashi, T. Kimura, K. Nakao, and T. Moritani, "Electrical stimulation of human lower extremities enhances energy consumption, carbohydrate oxidation, and whole body glucose uptake," Journal of Applied Physiology, vol. 96, no. 3, pp. 911-916, 2004.

[37] M. I. Lourencao, L. R. Battistella, C. M. de Brito, G. R. Tsukimoto, and M. H. Miyazaki, "Effect of biofeedback accompanying occupational therapy and functional electrical stimulation in hemiplegic patients," International Journal of Rehabilitation Research, vol. 31, no. 1, pp. 33-41, 2008.

[38] G. Alon, A. F. Levitt, and P. A. McCarthy, "Functional electrical stimulation (FES) may modify the poor prognosis of stroke survivors with severe motor loss of the upper extremity: a preliminary study," American Journal of Physical Medicine \& Rehabilitation, vol. 87, no. 8, pp. 627-636, 2008.

[39] J. S. Knutson, M. Y. Harley, T. Z. Hisel, and J. Chae, "Improving hand function in stroke survivors: a pilot study of contralaterally controlled functional electric stimulation in chronic hemiplegia," Archives of Physical Medicine and Rehabilitation, vol. 88, no. 4, pp. 513-520, 2007.

[40] M. R. Popovic, T. A. Thrasher, V. Zivanovic, J. Takaki, and V. Hajek, "Neuroprosthesis for retraining reaching and grasping functions in severe hemiplegic patients," Neuromodulation, vol. 8, no. 1, pp. 58-72, 2005.

[41] S. D. Iftime-Nielsen, M. S. Christensen, R. J. Vingborg, T. Sinkjaer, A. Roepstorff, and M. J. Grey, "Interaction of electrical stimulation and voluntary hand movement in SII and the cerebellum during simulated therapeutic functional electrical stimulation in healthy adults," Human Brain Mapping, vol. 33, no. 1, pp. 40-49, 2012.

[42] N. S. Makowski, J. S. Knutson, J. Chae, and P. Crago, "Neuromuscular electrical stimulation to augment reach and hand opening after stroke," Conference Proceedings: Annual International Conference of the IEEE Engineering in Medicine and Biology Society, vol. 2011, pp. 3055-3058, 2011.

[43] R. S. Calabro, V. C. Nibali, A. Naro et al., "Is non-invasive neuromuscular electrical stimulation effective in severe chronic neurogenic dysphagia? Reporton a post-traumatic brain injury patient," NeuroRehabilitation, vol. 38, no. 1, pp. 53-57, 2016.

[44] S. M. Albert, A. Im, L. Brenner, M. Smith, and R. Waxman, "Effect of a social work liaison program on family caregivers to people with brain injury," The Journal of Head Trauma Rehabilitation, vol. 17, no. 2, pp. 175-189, 2002.

[45] I. Sinnakaruppan, B. Downey, and S. Morrison, "Head injury and family carers: a pilot study to investigate an innovative community-based educational programme for family carers and patients," Brain Injury, vol. 19, no. 4, pp. 283-308, 2005.

[46] F. Baker, T. Wigram, and C. Gold, "The effects of a songsinging programme on the affective speaking intonation of people with traumatic brain injury," Brain Injury, vol. 19, no. 7, pp. 519-528, 2005.

[47] R. E. Hartman, "A brief history of behavioral assessment following experimental traumatic brain injury in juveniles," Translational Stroke Research, vol. 2, no. 4, pp. 433-437, 2011.
[48] A. Chodobski, B. J. Zink, and J. Szmydynger-Chodobska, "Blood-brain barrier pathophysiology in traumatic brain injury," Translational Stroke Research, vol. 2, no. 4, pp. 492516, 2011.

[49] L. Wang, X. Wang, H. Su et al., "Recombinant human erythropoietin improves the neurofunctional recovery of rats following traumatic brain injury via an increase in circulating endothelial progenitor cells," Translational Stroke Research, vol. 6, no. 1, pp. 50-59, 2015.

[50] C. An, X. Jiang, H. Pu et al., "Severity-dependent long-term spatial learning-memory impairment in a mouse model of traumatic brain injury," Translational Stroke Research, vol. 7, no. 6, pp. 512-520, 2016.

[51] E. S. Hald and P. W. Alford, "Smooth muscle phenotype switching in blast traumatic brain injury-induced cerebral vasospasm," Translational Stroke Research, vol. 5, no. 3, pp. 385-393, 2014.

[52] Y. Xiong, D. Lu, C. Qu et al., "Effects of erythropoietin on reducing brain damage and improving functional outcome after traumatic brain injury in mice," Journal of Neurosurgery, vol. 109, no. 3, pp. 510-521, 2008.

[53] Y. Xiong, A. Mahmood, D. Lu et al., "Histological and functional outcomes after traumatic brain injury in mice null for the erythropoietin receptor in the central nervous system," Brain Research, vol. 1230, pp. 247-257, 2008.

[54] M. Chopp, Y. Li, and J. Zhang, "Plasticity and remodeling of brain," Journal of the Neurological Sciences, vol. 265, no. 1-2, pp. 97-101, 2008.

[55] Z. G. Zhang, L. Zhang, Q. Jiang, and M. Chopp, "Bone marrowderived endothelial progenitor cells participate in cerebral neovascularization after focal cerebral ischemia in the adult mouse," Circulation Research, vol. 90, no. 3, pp. 284-288, 2002.

[56] Y. Fan, F. Shen, T. Frenzel et al., "Endothelial progenitor cell transplantation improves long-term stroke outcome in mice," Annals of Neurology, vol. 67, no. 4, pp. 488-497, 2010.

[57] B. E. Strauer, M. Brehm, T. Zeus et al., "Repair of infarcted myocardium by autologous intracoronary mononuclear bone marrow cell transplantation in humans," Circulation, vol. 106, no. 15, pp. 1913-1918, 2002.

[58] C. Kalka, H. Masuda, T. Takahashi et al., "Transplantation of ex vivo expanded endothelial progenitor cells for therapeutic neovascularization," Proceedings of the National Academy of Sciences of the United States of America, vol. 97, no. 7, pp. 3422-3427, 2000.

[59] M. Celik, N. Gokmen, S. Erbayraktar et al., "Erythropoietin prevents motor neuron apoptosis and neurologic disability in experimental spinal cord ischemic injury," Proceedings of the National Academy of Sciences of the United States of America, vol. 99, no. 4, pp. 2258-2263, 2002.

[60] A. K. Junk, A. Mammis, S. I. Savitz et al., "Erythropoietin administration protects retinal neurons from acute ischemiareperfusion injury," Proceedings of the National Academy of Sciences of the United States of America, vol. 99, no. 16, pp. 10659-10664, 2002.

[61] K. Satoh, Y. Kagaya, M. Nakano et al., "Important role of endogenous erythropoietin system in recruitment of endothelial progenitor cells in hypoxia-induced pulmonary hypertension in mice," Circulation, vol. 113, no. 11, pp. 1442-1450, 2006.

[62] L. Calvillo, R. Latini, J. Kajstura et al., "Recombinant human erythropoietin protects the myocardium from ischemia- 
reperfusion injury and promotes beneficial remodeling," Proceedings of the National Academy of Sciences of the United States of America, vol. 100, no. 8, pp. 4802-4806, 2003.

[63] E. Lipsic, P. van der Meer, R. H. Henning et al., "Timing of erythropoietin treatment for cardioprotection in ischemia/ reperfusion," Journal of Cardiovascular Pharmacology, vol. 44, no. 4, pp. 473-479, 2004.

[64] M. B. Potts, S. E. Koh, W. D. Whetstone et al., "Traumatic injury to the immature brain: inflammation, oxidative injury, and iron-mediated damage as potential therapeutic targets," NeuroRx, vol. 3, no. 2, pp. 143-153, 2006.

[65] K. J. Park, E. Park, E. Liu, and A. J. Baker, "Bone marrowderived endothelial progenitor cells protect postischemic axons after traumatic brain injury," Journal of Cerebral Blood Flow and Metabolism, vol. 34, no. 2, pp. 357-366, 2014.

[66] O. P. Akdemir, H. Oruckaptan, G. P. Ozdemir et al., "Effect of erythropoietin on brain tissue after experimental head trauma in rats," Surgical Neurology, vol. 68, no. 5, pp. 547-555, 2007, 555.

[67] F. H. Bahlmann, K. De Groot, J. M. Spandau et al., "Erythropoietin regulates endothelial progenitor cells," Blood, vol. 103, no. 3, pp. 921-926, 2004.

[68] L. Wang, Z. Zhang, R. Zhang et al., "Erythropoietin upregulates SOCS2 in neuronal progenitor cells derived from SVZ of adult rat," Neuroreport, vol. 15, no. 8, pp. 12251229, 2004.

[69] T. Sobrino, O. Hurtado, M. A. Moro et al., "The increase of circulating endothelial progenitor cells after acute ischemic stroke is associated with good outcome," Stroke, vol. 38, no. 10, pp. 2759-2764, 2007.

[70] N. Andelic, E. Bautz-Holter, P. Ronning et al., "Does an early onset and continuous chain of rehabilitation improve the long-term functional outcome of patients with severe traumatic brain injury?" Journal of Neurotrauma, vol. 29, no. 1, pp. 66-74, 2012. 

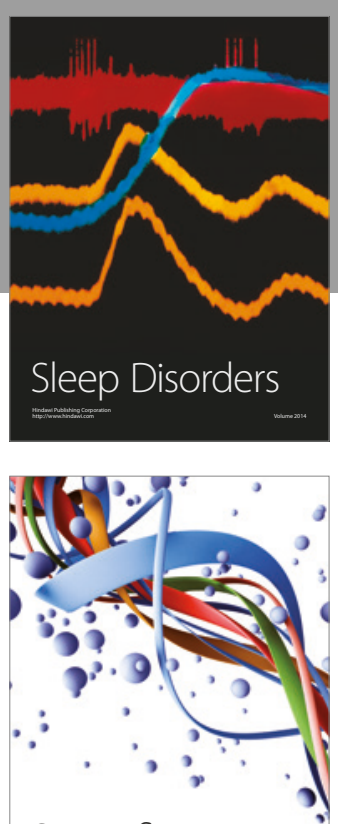

Scientifica
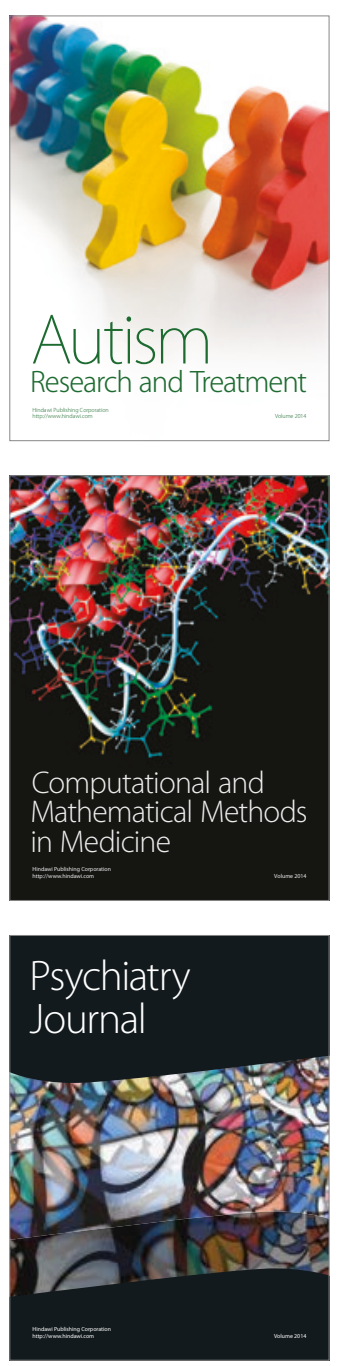
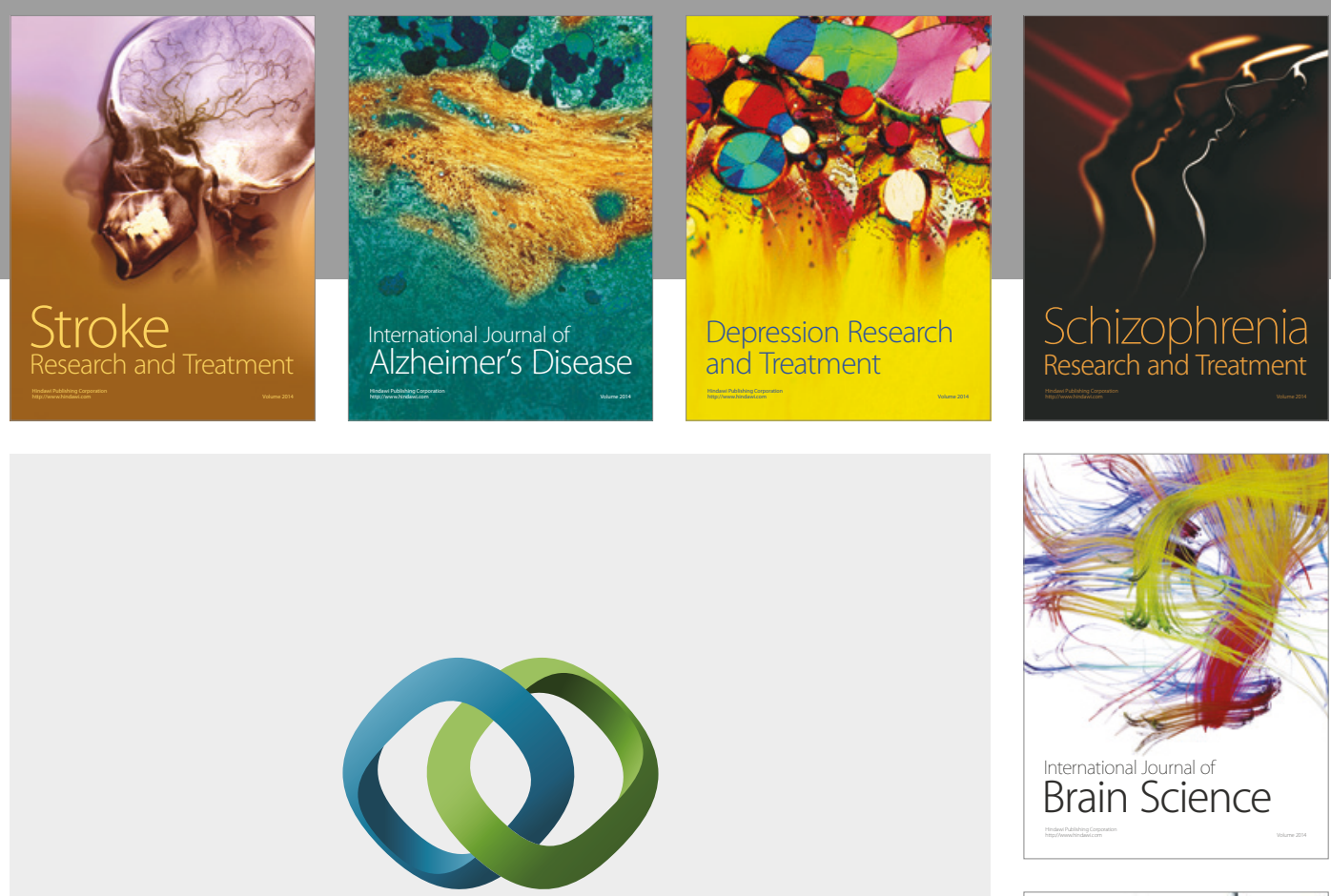

\section{Hindawi}

Submit your manuscripts at

https://www.hindawi.com
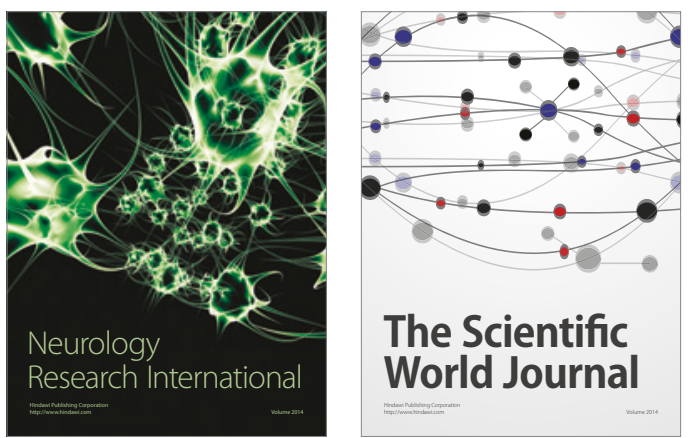

The Scientific World Journal

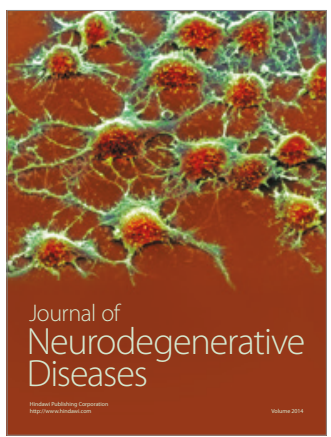

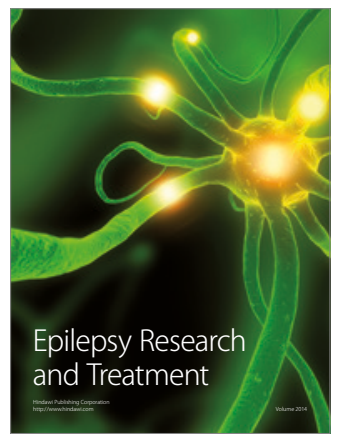

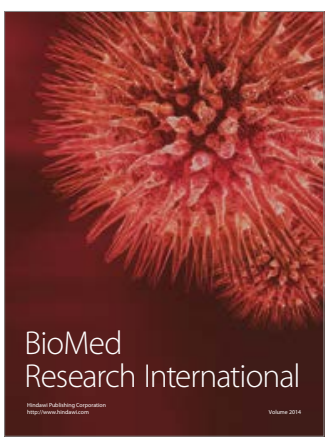

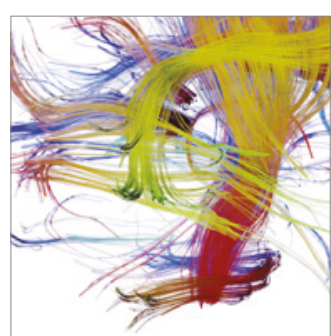

Brain Science

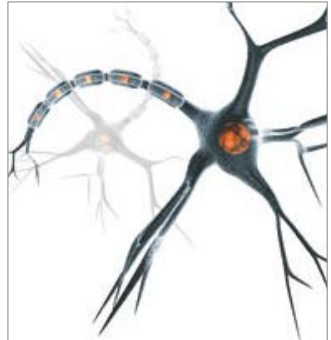

Neural Plasticity
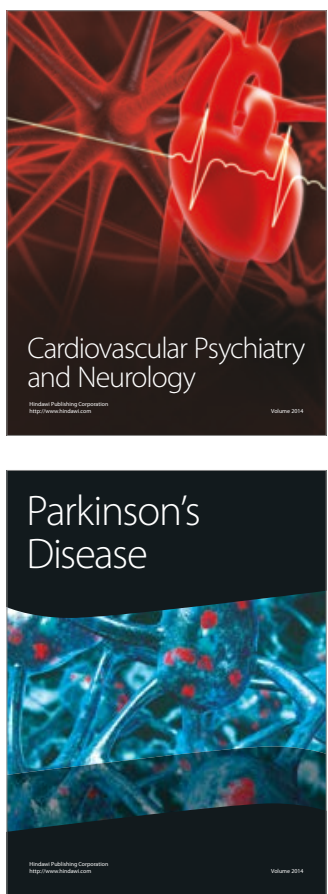